\title{
ArcheoSciences
}

Revue d'archéométrie

33 (suppl.) | 2009

Mémoire du sol, espace des hommes

\section{Optimum Electrical Resistivity Tomography (OERT) approach using combination of different arrays in archaeological investigations}

Meriç A. Berge and Mahmut G. Drahor

\section{CpenEdition}

Journals

Electronic version

URL: https://journals.openedition.org/archeosciences/1667

DOI: 10.4000/archeosciences. 1667

ISBN: 978-2-7535-1599-4

ISSN: $2104-3728$

Publisher

Presses universitaires de Rennes

Printed version

Date of publication: 30 October 2009

Number of pages: 263-265

ISBN: 978-2-7535-0943-6

ISSN: $1960-1360$

Electronic reference

Meriç A. Berge and Mahmut G. Drahor, "Optimum Electrical Resistivity Tomography (OERT) approach using combination of different arrays in archaeological investigations", ArcheoSciences [Online], 33 (suppl.) | 2009, Online since 30 October 2011, connection on 21 September 2021. URL: http:// journals.openedition.org/archeosciences/1667 ; DOI: https://doi.org/10.4000/archeosciences. 1667 


\title{
Optimum Electrical Resistivity Tomography (OERT) approach using combination of different arrays in archaeological investigations
}

\author{
Meriç A. Berge ${ }^{*, * *}$ and Mahmut G. Drahor ${ }^{*, * *}$
}

Key words: Optimum Electrical Resistivity Tomography, Electrode array, Sensitivity.

In this study, the optimum electrical resistivity tomography (OERT) concept was analyzed by combining different electrode arrays in terms of sensitivity in archaeological cases. More than a hundred electrode arrays were classified by Szalai \& Szarka (2008), investigating the superposition, focusing and linearity problem. Also, Dahlin \& Zhou (2004) compared images resulting from various configurations. However, the difficulties posed by apparent resistivity due to different characteristics of electrode arrays, resulting in different anomaly shapes and resistivity values, revealed that some optimisation techniques in tomographic inversion are necessary to obtain more interpretable results.

The electrical resistivity tomography method has been widely used recently together with magnetic and groundpenetrating radar for detailed investigation of archaeological sites. Faster data acquisition has been facilitated by the development of multi-electrode towed and wheeled systems. However, in 3-dimensional surveys, the inversion technique demands much computing time. Also, these new systems permit the use of different electrode configurations for single or multiple usage in data acquisition. Hence, data sets are importantly increased, and the usage of optimum electrical resistivity tomography optimisations might give more useful results than the standard single array utilisations.
Commonly used arrays (Wenner, Wenner-Schlumberger, dipole-dipole, pole-pole) and non-conventional arrays (gradient, square, etc.) could also be inverted by commercial software using joint or weighted inversion described by some researchers (Athanasiou et al., 2007; de la Vega et al., 2003; Stummer et al., 2004). Sensitivity analyses led us to select suitable electrode configurations for a field survey. The subsurface sensitivity between the electrodes inserted on the surface gives the degree of resistivity change in the subterranean section of the investigation line. Sensitivity values are also used to obtain the depth of investigation for different electrode arrays (Roy \& Apparao, 1971; Edwards, 1977; Barker, 1991). The superiority of the arrays (horizontal-vertical resolution, data coverage, depth of investigation) plays a critical and important role in choosing a suitable array. In order to image an architectural plan using ERT studies, this concept should be had very important role because of the archaeological context is very complex.

Two and three-dimensional ERT studies have been carried out in Bayraklı Höyük (İzmir/Turkey) showing the complex structural settlement in three dimensions of the subsurface. Sensitivity analyses on a real case were also performed. It should be pointed out that the highest sensitivity values are observed as very near to the surface. For

*Center for Near Surface Geophysics and Archaeological Prospection, Dokuz Eylül University. (meric.berge@deu.edu.tr) (goktug.drahor@deu.edu.tr)

** Dokuz Eylül University, Engineering Faculty, Department of Geophysical Engineering. 
different arrays, these values demonstrate critical changes in the sensitivity sections. Data acquisition was performed with a 30-channel resistivity meter using electrode and line intervals of $1 \mathrm{~m}$ and $0.5 \mathrm{~m}$, respectively. Resistivity data was processed using robust inversion algorithm minimizing the absolute values of differences between observed and calculated data in an iterative manner. These processes were achieved by Res2Dinv and Res3Dinv softwares (Geotomo, 2005). Inversion of the field data was carried out up to 10 iterations and absolute error values (ABS) did not exceed $6.5 \%$.

In Figure 1, 2D ERT and sensitivity results are given for a measuring line using Wenner and dipole-dipole electrode arrays. We used 96 apparent resistivity data for the Wenner array, while the dipole-dipole included 105 datum points. The results show that resistive structures ( $>75 \mathrm{ohm} . \mathrm{m}$ ) lie approximately between $0.25-2.25 \mathrm{~m}$ depth. The conductive layer following resistive strata starts at $2.25 \mathrm{~m}$ depth (Fig. $1)$. There are slight differences between the sensitivity sections of the Wenner and the dipole-dipole arrays in Figure 1. Compared to the dipole-dipole array, the Wenner array presents low sensitive values in shallower layers (between 0 and $1 \mathrm{~m}$ ) and higher sensitive values in medium depths (1 and $2 \mathrm{~m}$ ). Both arrays also have less sensitive values in the deeper parts $(>2 \mathrm{~m})$ of the sections (Fig. 1).

A larger data set (519 datum points) was obtained after combining Wenner, Wenner-Schlumberger, dipole-dipole, pole-pole and pole-dipole arrays. The model resistivity section of combined data was changed importantly according to single array uses (Fig. 2a). This case might be related to discrepancy of relative sensitivities according to used arrays in ERT sections. In order to avoid this, we therefore calculated the arithmetic means of whole model sections and their sensitivities (Fig. 2b). Whole sections demonstrated that the resistive and conductive structures increase or decrease according to the number and types of array used in combined array modification. This situation might produce some pseudo-structures related to array type and data quality in the model sections. Although, the relative sensitivities of combined usage are slightly high from the arithmetic mean section, the arithmetic mean results are rather stable in terms of sensitivity. Therefore, we think that this stability might produce more reliable models.
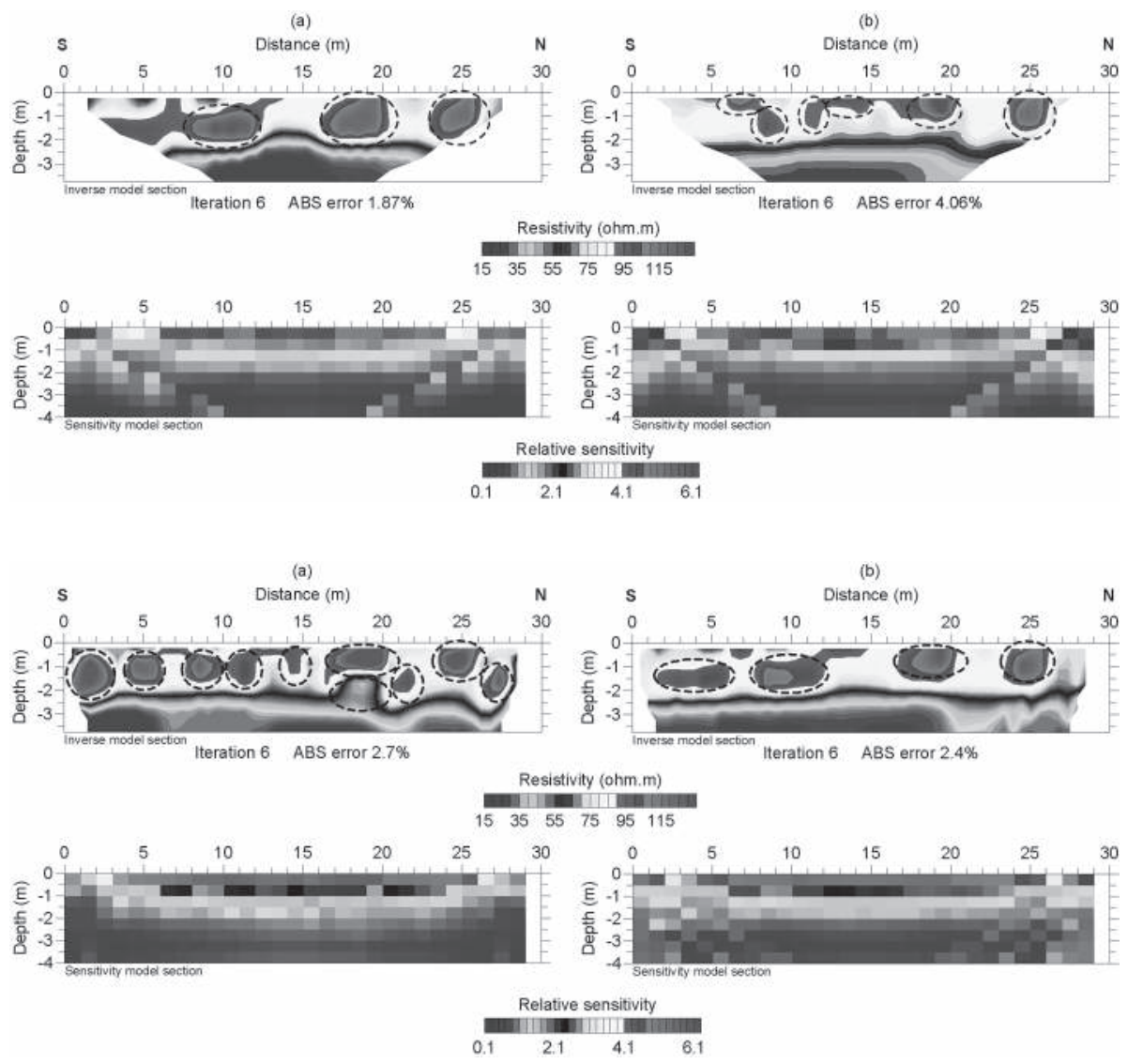

Figure 1 (see color plate): Inversion and sensitivity model sections of a) Wenner and b) dipole-dipole arrays.

Figure 2 (see color plate): Inversion and sensitivity model sections of a) combined form and b) arithmetic mean of arrays (Wenner, WennerSchlumberger, dipole-dipole, pole-pole and pole-dipole). 


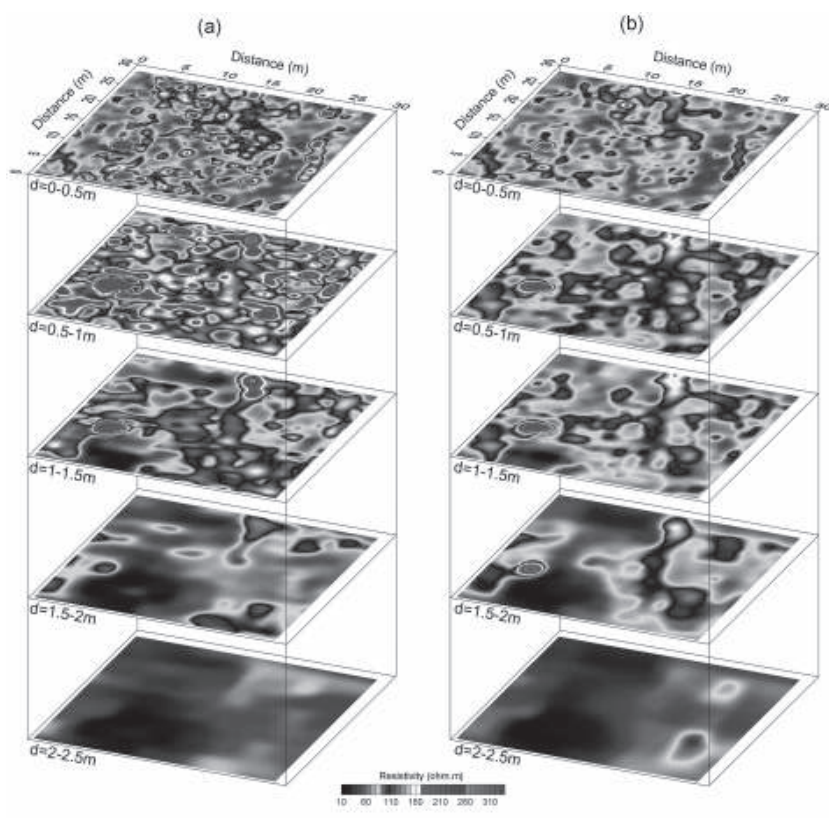

Figure 3 (see color plate): Inversion and sensitivity model depth slices of a) combined form and b) arithmetic mean of arrays (Wenner, Wenner-Schlumberger, dipole-dipole and pole-pole). ABS error values are $3.5 \%$ and $3.75 \%$, respectively.

Three-dimensional ERT investigation data sets were collected from the parallel measuring lines for different arrays, and then processed by $3 \mathrm{D}$ robust algorithm up to six iterations. To obtain more reliable models and sensitivity sections, similar optimisations were also applied to the $3 \mathrm{D}$ results. The model slices obtained from combined usage and arithmetic mean approach are presented for different depth slices in Fig. 3. As can be seen from this figure, the arithmetic mean process gives more successful results than the combined usage of ERT. Especially, the depth slices obtained by combined process are still complex, and architectural plan could not be distinguished as well as the arithmetic mean approach for first three slices.

Therefore, the optimum electrical resistivity tomography (OERT) experiments revealed that the combined usage of different electrode arrays would not be useful in every situation. These experiments showed that an optimum approximation such as arithmetic mean approach might produce more reliable results than single array and combined usages in archaeological applications.

\section{References}

Athanasiou, E. N., Tsourlos, P. I., Papazachos and C. B., TsoKas, G. N., 2007. Combined weighted inversion of electrical resistivity data arising from different array types. Journal of Applied Geophysics, 62: 124-140.

BARKER, R. D., 1991. Depth of investigation of collinear symmetrical four-electrode arrays. Geophysics, 54: 1031-1037.

DAhlin, T. and Zhou, B., 2004. A numerical comparison of $2 \mathrm{D}$ resistivity imaging with 10 electrode arrays. Geophysical Prospecting, 52: 379-398.

EDWARDS, L. S., 1977. A modified pseudosection for resistivity and IP, Geophysics, 42: 1020-1036.

de la Vega, M., Osella, A. and Lascano, E., 2003. Joint inversion of Wenner and dipole-dipole data to study a gasolinecontaminated soil. Journal of Applied Geophysics, 54: 97-109.

Roy, A. and Apparao, A., 1971. Depth of investigation in direct current methods. Geophysics, 36: 943-959.

Geotomo Software, 2005. Res2Dinv, Res3Dinv. From http:// www.geoelectrical.com, 02/2009.

Stummer, P., Maurer, H. and Green, A., 2004. Experimental design. Electrical resistivity data sets that provide optimum subsurface information. Geophysics, 69 (1): 120-139.

SzALAI, S. and Szarka, L., 2008. On the classification of surface geoelectric arrays. Geophysical Prospecting, 56: 159-175. 